\title{
Platelet Activating Factor Production and Proinflammatory Gene Expression in Endotoxin-Challenged Bovine Mammary Endothelial Cells
}

\author{
C. M. Corl, J. C. Gandy, and L. M. Sordillo ${ }^{1}$ \\ Large Animal Clinical Sciences, College of Veterinary Medicine, Michigan State University, East Lansing 48824
}

\begin{abstract}
The bovine mammary gland responds to gram-negative pathogens by stimulating the production of cytokines and other proinflammatory mediators that orchestrate the migration of leukocytes into tissues. Platelet activating factor (PAF), interleukin $1 \beta$ (IL-1 $\beta$ ), IL-8, and intercellular adhesion molecule 1 (ICAM1) are among the several inflammatory factors involved in the early activation and migration of leukocytes into the mammary gland during the initial stages of coliform mastitis. Several different cell types within the mammary gland are capable of expressing these potent proinflammatory mediators. The objective of this study was to characterize the expression profile of vascular-derived inflammatory molecules that may play a role in the pathogenesis of bovine coliform mastitis. Isolated bovine mammary gland endothelial cells were stimulated in culture for up to $12 \mathrm{~h}$ with endotoxin obtained from Escherichia coli, and the temporal expression of proinflammatory cytokines and adhesion molecules relative to endogenous PAF biosynthesis was evaluated. Results from the in vitro time course experiment showed that vascular-derived PAF biosynthesis began as early as $30 \mathrm{~min}$ and peaked at $1 \mathrm{~h}$ following endotoxin challenge. The biosynthesis of PAF preceded the endotoxin-induced IL-1 $\beta$, IL-8, and ICAM1 mRNA expression that increased after $1 \mathrm{~h}$ and reached peak expression between 4 and $12 \mathrm{~h}$ following stimulation. Inhibiting the effects of endogenous PAF with a receptor antagonist suggests that vascular-derived PAF is an early proinflammatory mediator that plays at least a partial role in the subsequent expression of IL-1 $\beta$, IL-8, and ICAM1 during endotoxin challenge. Furthermore, endotoxin-induced PAF biosynthesis by bovine mammary gland endothelial cells is regulated to some extent by phospholipase $\mathrm{D}$ activity and phosphatidic acid production. The results from this study support the contention that mammary gland endothelial cells can con-
\end{abstract}

Received January 31, 2008.

Accepted April 12, 2008.

${ }^{1}$ Corresponding author: sordillo@msu.edu tribute to the production of important proinflammatory mediators that are typically associated with coliform mastitis.

Key words: platelet activating factor, mastitis, cytokine, endothelium

\section{INTRODUCTION}

Bovine coliform mastitis is a serious problem affecting the dairy industry because it is severe, sometimes fatal, and difficult to control with antibiotics formulated for intramammary use. The acute symptoms associated with coliform mastitis result from the rapid growth of the organism, the release of endotoxin, and the subsequent development of an unlimited inflammatory reaction (Smith et al., 1984; Hogan and Larry Smith, 2003). Endotoxin derived from the outer membrane of gramnegative bacteria initiates the nonspecific acute phase response by evoking the synthesis of eicosanoids, cytokines, and other proinflammatory molecules at the foci of infection. These potent mediators can regulate local inflammatory reactions by intercellular communication, but can also gain access to the circulation and induce systemic responses. An exaggerated acute or protracted local inflammatory response can cause extensive necrosis of mammary parenchymal tissue and loss of milk production (Hill et al., 1984). Some of the acute systemic symptoms of coliform mastitis that are directly or indirectly induced by the stimulated release of acute phase molecules include fever, depression, respiratory distress, reduced rumen motility, metabolic disturbances, and death (Lohuis et al., 1990). Several acute phase mediators produced during endotoxemia are especially associated with the severity of disease. For example, both milk and sera tumor necrosis factor $\alpha(\mathbf{T N F} \boldsymbol{\alpha})$, interleukin $1 \beta(\mathbf{I L}-\mathbf{1} \boldsymbol{\beta})$, and interleukin 8 (IL-8) concentrations are associated closely with the manifestation of acute symptoms of coliform mastitis (Sordillo and Peel, 1992; Shuster et al., 1996; Riollet et al., 2000).

Vascular endothelial cells are one of the key cell types involved in both acute and chronic disease processes because of the ability to control the extravasation of leukocytes from the circulation and into tissues. The 
normal endothelium produces a variety of proteins, prostanoids, and other paracrine substances needed to maintain a delicate balance between vasodilation and vasoconstriction, coagulation and blood fluidity, and leukocyte adhesion and migration. The vascular endothelium, however, is a primary target for endotoxin during the pathogenesis of gram-negative bacteria. Endotoxin interacts with Toll-like receptor-4 expressed by vascular tissues to activate the transcriptional regulation of endothelial cell-derived inflammatory mediators (Grandel and Grimminger, 2003; Rainard and Riollet, 2006). Vascular-derived proinflammatory cytokines and adhesion molecules are needed to recruit activated leukocytes to the site of infection for prompt pathogen elimination. Protracted exposure to large quantities of endotoxin, however, can cause a hyperactive proinflammatory response by endothelial cells that can lead to severe tissue damage and endotoxic shock (Grandel and Grimminger, 2003). Several previous studies described a significant increase in both IL- $1 \beta$ and IL-8 in the milk and mammary tissue of cattle following intramammary inoculation of endotoxin or Escherichia coli (Riollet et al., 2000; Lee et al., 2006). These proinflammatory cytokines also have been implicated as key players in both acute and chronic vascular inflammatory responses (Braquet et al., 1989a; Cines et al., 1998). Numerous studies have shown that IL- $1 \beta$ has potent proinflammatory effects on endothelial cells and is considered instrumental in the propagation of the inflammatory milieu within vascular tissues during pathology (Reinhart et al., 2002; von der Thusen et al., 2003). This cytokine also can greatly increase leukocyte adhesion to endothelial cells by enhancing the expression of the Ig superfamily of adhesion molecules including intercellular adhesion molecule 1 (ICAM1) and vascular adhesion molecule 1 (VCAM1) (von der Thusen et al., 2003). Both ICAM1 and VCAM1 are involved in increasing the adhesive nature of leukocyte-endothelial cell interactions resulting in cellular activation and extravasation into affected tissues. The enhanced expression of IL-8 also was correlated to leukocyte migration and inflammation in bovine mammary glands, and several studies showed that IL-8 is an important chemokine involved in the attraction of neutrophils during mastitis (Persson et al., 1993; Caswell et al., 1999; von der Thusen et al., 2003).

Ample evidence exists to support an early role of vascular-derived platelet activating factor (PAF) in the pathophysiology of endotoxemia as well. Platelet activating factor is a potent phospholipid mediator produced by many cells involved in inflammatory reactions (Cines et al., 1998). The vascular endothelium is both a target for and a cellular source of this potent proinflammatory biological response modifier. Whereas low levels of PAF are required for appropriate inflammatory responses, overproduction of PAF can be toxic and has been associated with several inflammatory-based diseases including atherosclerosis, myocardial infarction, and septic shock (Braquet et al., 1989a; Kingsnorth, 1996). Indeed, PAF activates the recruitment and increases adhesion of circulating monocytes that can "prime" tissues for enhanced synthesis and secretion of cytokines such as TNF $\alpha$, IL-1 $\beta$, and IL-8 (Snyder, 1995). Moreover, both TNF $\alpha$ and IL- $1 \beta$ can increase the synthesis and release of PAF from endothelial cells in the absence of other stimulation (Bussolino et al., 1988). Previous studies also suggest that $\mathrm{PAF}, \mathrm{TNF} \alpha$, and IL-1 $\beta$ may create a positive feedback loop in human umbilical vein endothelial cells that can perpetuate acute and chronic inflammation (Braquet et al., 1989b; Cines et al., 1998). Direct injection of PAF into animal models also was shown to mimic the effects of endotoxin challenge, whereas $\mathrm{PAF}$ receptor antagonists were able to decrease endotoxin-induced mortality (Kruse-Elliott et al., 1996; Snapper et al., 1998). Relative to mastitis, earlier studies demonstrated a significant role for PAF and IL- $1 \beta$ in the accumulation of neutrophils in endotoxin-challenged bovine mammary tissues (Persson et al., 1993; Waller, 1997). The cellular source of PAF in mammary tissues, however, has not been defined.

The recruitment and activation of neutrophils during the early stages of infection are critical for determining the outcome of coliform mastitis (Hill et al., 1984). Vascular endothelial cells play a pivotal role in microenvironment homeostasis by regulating the trafficking of these cells and other molecules between the blood stream and tissues. Although it is likely that endothelial cells play a critical role in the duration and severity of mastitis, very little information is available to establish the significance of bovine mammary endothelial cells (BMEC) to dairy cattle defense against coliform infection (Maddox et al., 1999; Lee et al., 2000; Monfardini et al., 2002). The importance of PAF in promoting leukocyte-endothelial cell interactions by increasing the production of proinflammatory cytokines and adhesion molecules has not been defined with respect to bovine mammary innate defense. The present study investigated the relationship of vascular-derived PAF biosynthesis with the expression of proinflammatory cytokines and adhesion molecules in BMEC following exposure to endotoxin.

\section{MATERIALS AND METHODS}

\section{Chemicals and Reagents}

Antibiotics and antimycotics, trypsin-EDTA, HEPES buffer, and Ham's F-12K (Kaighn's Nutrient Mixture F-12) were purchased from Cellgro (Herndon, VA). 
Hyclone Laboratory (Logan, UT) supplied fetal bovine serum (FBS). The synthetic PAF-16 (1-O-hexadecyl-2acetyl-sn-glycero-3-phosphocholine, $\mathrm{C}_{26} \mathrm{H}_{54} \mathrm{NO}_{7} \mathrm{P}$, molecular weight 523.7) and the competitive $\mathrm{PAF}$ receptor antagonist, CV3988, were purchased from BIOMOL (Plymouth Meeting, PA). The phosphatidic acid (PA) was from Avanti Polar Lipids (Alabaster, AL). Precoated silica gel G $150 \AA$ plates were purchased from Whatman Laboratory (Clifton, NJ). Radiolabeled $\left[1-{ }^{14} \mathrm{C}\right]$ acetyl-coenzyme A (specific activity 5,500 dpm/ $\mathrm{nmol}$ ) and $\left[1-{ }^{14} \mathrm{C}\right]$ arachidonic acid (specific radioactivity $51.7 \mathrm{mCi} / \mathrm{mmol}$ ) were purchased from GE Life Sciences (Piscataway, NJ). The RNeasy Plus Mini Kit for isolation of RNA was purchased from Qiagen (Valencia, CA). Reagents for real-time PCR were purchased from Applied Biosystems (Foster City, CA). All other chemicals were purchased from Sigma Chemical (St. Louis, MO).

\section{BMEC Culture System}

Endothelial cells were isolated from the bovine supramammary artery by collagenase digestion and purified through cloning techniques using the limited dilution method as described previously (Aherne et al., 1995). Briefly, isolated cells were grown in a T25 culture flask at $37^{\circ} \mathrm{C}$ with $5 \% \mathrm{CO}_{2}$. Once cells reached 75 to $90 \%$ confluence, they were harvested and transferred into a 96-well tissue culture plate at a dilution of 0 to 2 cells/ well. Once confluent, these cells were consecutively passed in 24-well plates, 6 -well plates, and T25 culture flasks before cryopreservation. The purified BMEC were then cultured and stimulated in F-12K medium containing 5\% FBS, antibiotics and antimycotics (100 $\mathrm{U} / \mathrm{mL})$, heparin $(100 \mu \mathrm{g} / \mathrm{mL})$, insulin $(10 \mu \mathrm{g} / \mathrm{mL})$, transferrin $(5 \mu \mathrm{g} / \mathrm{mL})$, and sodium selenite $(10 \mathrm{ng} / \mathrm{mL})$.

For experimental use, BMEC were seeded at $2.5 \times$ $10^{6}$ cells per $100-\mathrm{mm}$ dish the day before stimulation. The effect of endotoxin was evaluated upon stimulation with LPS ( $E$. coli O111:B4) at a concentration of 100 $\mathrm{ng} / \mathrm{mL}$ for various time periods $(0,0.5,1,4,6$, or $12 \mathrm{~h})$. To determine the role of PAF in endotoxin-mediated gene expression of proinflammatory molecules, synthetic PAF-16 and a PAF receptor antagonist, CV-3988, were utilized. Both chemicals were reconstituted in ethanol at the recommended concentrations, $100 \mathrm{mg} / \mathrm{mL}$ for PAF-16 and $15 \mathrm{mg} / \mathrm{mL}$ for CV-3988, before use. Synthetic PAF-16 was added to BMEC at a final concentration of $1 \mathrm{n} M$ for $4 \mathrm{~h}$ before RNA extraction. The PAF receptor antagonist, CV-3988, was used at a final concentration of $10 \mathrm{n} M$ in conjunction with LPS, $100 \mathrm{ng} /$ $\mathrm{mL}$, for $1 \mathrm{~h}$ before RNA extraction. The role of potential upstream mediators of Lyso-PAF-AcT activity following endotoxin stimulation was verified by the exogenous addition of synthetic PA and inhibition of phospholipase D (PLD) by a selective chemical inhibitor, calphostin C. Phosphatidic acid, reconstituted in chloroform at 25 $\mathrm{mg} / \mathrm{mL}$, was added to BMEC at a final concentration of $60 \mathrm{u} M$ in F12K after being dried down under a stream of nitrogen and briefly sonicated (10 s) with a probe sonicator. Following a 2-h pretreatment with PA, the BMEC were stimulated with LPS, $100 \mathrm{ng} / \mathrm{mL}$, for $1 \mathrm{~h}$. Calphostin $\mathrm{C}$ was reconstituted in DMSO and added to BMEC at a final concentration of $150 \mathrm{n} M$ in F12K, whereas the vehicle control contained the equivalent amount of DMSO, for $1 \mathrm{~h}$ before LPS stimulation, 100 $\mathrm{ng} / \mathrm{mL}$, for $1 \mathrm{~h}$.

\section{Determination of Lyso-PAF Acetyl Coenzyme A Acetyltransferase Activity}

The Lyso-PAF acetyl coenzyme A acetyltransferase (Lyso-PAF-AcT) activity was determined by measuring the amount of radioactive PAF produced by the reaction of BMEC homogenate with radioactive substrate $\left(\left[1-{ }^{14} \mathrm{C}\right]\right.$ acetyl-CoA $)$ as described previously (Corl et al., 2003). Briefly, cells were seeded at $2.5 \times 10^{6}$ cells per $100-\mathrm{mm}$ dish the day before stimulation and harvested by scraping in $0.6 \mathrm{~mL}$ of $0.1 \mathrm{M}$ Tris- $\mathrm{HCl}$ buffer, $\mathrm{pH} 7.4$, followed by sonication. The assay mixture contained $0.1 \mathrm{M}$ Tris- $\mathrm{HCl}, 200 \mathrm{nmol}\left[1-{ }^{14} \mathrm{C}\right]$ acetylcoenzyme A, $100 \mathrm{nmol}$ of Lyso-PAF, and $0.5 \mathrm{~mL}$ of the BMEC homogenate. The reaction was incubated for 30 min at $37^{\circ} \mathrm{C}$ after which time it was stopped by the addition of $4 \mathrm{~mL}$ of cold chloroform/methanol (2:1) and $1.5 \mathrm{~mL}$ of water. The mixture was vortexed and centrifuged $(750 \times g)$ for $15 \mathrm{~min}$. Upon phase separation, the organic layer was evaporated under a nitrogen stream, resuspended in $25 \mu \mathrm{L}$ of chloroform/methanol (2:1), and loaded onto a silica gel $150 \AA$ plate. The plate was run in a chloroform/methanol/acetic acid/water (50:25:8:4) solvent system and visualized following exposure to a Kodak phosphor storage screen. Bands corresponding to a PAF standard were analyzed using the Bio-Rad Personal Molecular Imager System and Quantity One 1-D Analysis Software (Bio-Rad, Hercules, CA). Data were calculated based on volume $\times \mathrm{mm}^{2} / \mu \mathrm{g}$ of protein and expressed as fold induction compared with the control.

\section{PAF-Acetylhydrolase Activity Assay}

The activity of PAF-acetylhydrolase (PAF-AH) was measured in BMEC homogenates following stimulation with endotoxin $(100 \mathrm{ng} / \mathrm{mL})$. The BMEC were seeded at $2.5 \times 10^{6}$ cells $/ 100-\mathrm{mm}$ dish $24 \mathrm{~h}$ before stimulation. Following endotoxin stimulation, BMEC were collected in $1 \mathrm{~mL}$ of PBS using a cell scraper. Upon homogeniza- 
tion with a sonicator, the homogenate was filtered through a 10,000 MW concentrator $(10,000 \times g)$ for 15 min, and the supernatant was utilized in the PAF Acetylhydrolase Assay Kit (Cayman Chemical, Ann Arbor, MI). Briefly, the assay utilizes 2-Thio PAF as a substrate and detects free thiols using 5,5'-dithio-bis(2nitrobenzoic acid; DTNB) following hydrolysis of the acetyl-thioester bond at the $s n-2$ position by PAF-AH. The assay was run in a 96 -well plate combining $10 \mu \mathrm{L}$ of sample (10 to $20 \mu \mathrm{g}$ of total protein), $5 \mu \mathrm{L}$ of assay buffer, and initiated by the addition of $200 \mu \mathrm{L}$ of the 2-Thio PAF substrate. After gently shaking the plate for $30 \mathrm{~s}$, the plate was covered and incubated at room temperature for $30 \mathrm{~min}$. The reaction was developed by incubating with $10 \mu \mathrm{L}$ of DTNB for $1 \mathrm{~min}$ and read on the Wallac Victor3 plate reader at $405 \mathrm{~nm}$. The assay is capable of detecting changes of $\mathrm{PAF}-\mathrm{AH}$ activity ranging from 0.02 to $0.2 \mu \mathrm{mol} / \mathrm{min} / \mathrm{mL}$, which is equivalent to an absorbance increase of 0.01 to $0.1 \mathrm{per} \mathrm{min}$. The reaction is linear to at least 1.2 absorbance units. A positive control consisting of $10 \mu \mathrm{L}$ of human PAF-AH was included in all assays. The BMEC homogenates were diluted or concentrated accordingly so that the sample absorbance would fall within the detectable limits of the assay. The activity of PAF-AH was expressed as micromoles/minute/gram of protein.

\section{Phospholipase D Activity Assay}

The PLD activity in BMEC was measured by quantifying $\left[1-{ }^{14} \mathrm{C}\right]$ arachidonic acid labeled phosphatidylethanol (PEt), which was produced endogenously by BMEC in the presence of ethanol and endotoxin. The cells were prepared at $5 \times 10^{6}$ cells in $1.0 \mathrm{~mL}$ of F12-K and prelabeled with $\left[1-{ }^{14} \mathrm{C}\right]$ arachidonic acid $(0.5 \mu \mathrm{Cu} / \mathrm{mL})$ for 1 $\mathrm{h}$ at $37^{\circ} \mathrm{C}$. The reaction was initiated by the addition of $5.0 \%$ ethanol for $15 \mathrm{~min}$ at $20^{\circ} \mathrm{C}$ followed by endotoxin (100 ng/mL) in $5 \% \mathrm{FBS}$ for $3 \mathrm{~h}$ at $37^{\circ} \mathrm{C}$. The samples were centrifuged $(750 \times g)$ for $10 \mathrm{~min}$ at which time the supernatant was discarded and the cells were resuspended in $1 \mathrm{~mL}$ of cold methanol with $1 \%$ hydrochloric acid. Following the addition of $0.5 \mathrm{~mL}$ of water and 2 $\mathrm{mL}$ of chloroform, the mixture was vortexed and centrifuged $(750 \times g)$ for $15 \mathrm{~min}$. Upon phase separation, the organic layer was evaporated under a nitrogen stream, resuspended with $25 \mu \mathrm{L}$ of chloroform/methanol (2:1), and loaded onto a silica gel $150 \AA$ plate. The plate was run in an ethyl acetate/2,2,4-trimethyl pentane/acetic acid/water (11:5:2:10) solvent system and visualized following exposure to a Kodak phosphor storage screen. Bands corresponding to a PEt standard were analyzed using the Bio-Rad Personal Molecular Imager System and Quantity One 1-D Analysis Software (Bio-Rad). Data were calculated based on volume $\times \mathrm{mm}^{2} / 5 \times 10^{6}$ cells and expressed as fold induction compared with the control.

\section{Measurement of PA Formation}

Phosphatidic acid formation was determined by measuring the amount of radioactive PA produced by BMEC. The cells were prepared at $5 \times 10^{6}$ cells in 1.0 $\mathrm{mL}$ of $\mathrm{F} 12-\mathrm{K}$ and prelabeled with $\left[1-{ }^{14} \mathrm{C}\right]$ arachidonic acid $(0.5 \mu \mathrm{Ci} / \mathrm{mL})$ at $37^{\circ} \mathrm{C}$ for $1 \mathrm{~h}$. The reaction was initiated by the addition of endotoxin $(100 \mathrm{ng} / \mathrm{mL})$ and incubated for $30 \mathrm{~min}$. The reaction was stopped as in the PLD assay and vigorously mixed. Finally, the reaction mixtures were centrifuged $(750 \times g)$ for 15 min for phase separation, and the organic layer was evaporated under a nitrogen stream. The extracted samples were resuspended with $25 \mu \mathrm{L}$ of chloroform/methanol (2:1) and loaded onto a silica gel $150 \AA$ plate. The plate was run in a chloroform/methanol/acetic acid (65:15:2) solvent system and visualized following exposure to a Kodak phosphor storage screen. Bands corresponding to a PA standard were analyzed using the Bio-Rad Personal Molecular Imager System and Quantity One 1-D Analysis Software (Bio-Rad). Data was calculated based on volume $\times \mathrm{mm}^{2} / 5 \times 10^{6}$ cells and expressed as fold induction compared with the control.

\section{Gene Transcript Quantification by Real-Time PCR}

Following stimulation, BMEC RNA was extracted for quantification of IL-8, IL-1 $\beta$, and ICAM1 mRNA transcript expression by real-time PCR. Briefly, total RNA was extracted utilizing the Qiagen RNeasy Plus Mini Kit (Qiagen, Valencia, CA), which included an in-column genomic DNA elimination treatment. Purified RNA was converted to cDNA using the Applied Biosystems High Capacity cDNA Archive Kit (Applied Biosystems, Foster City, CA). All real-time PCR assays were conducted utilizing TaqMan gene expression assays from Applied Biosystems. Briefly, TaqMan primer and probe sets (Table 1) were designed from bovine sequences with the Applied Biosystems Pipeline software and synthesized by Applied Biosystems. Samples were assayed in triplicate with $100 \mathrm{ng}$ of cDNA per reaction along with $10 \mu \mathrm{L}$ of TaqMan Fast Universal PCR Master Mix (2×), and $1 \mu \mathrm{L}$ of the appropriate TaqMan Gene Expression Assay Mix (20×) on the Applied Biosystems 7500 Fast Real-Time PCR System. The relative quantification of each gene was calculated utilizing the 7500 Fast SDS Software (version 1.3.1). Data were calculated based on the comparative $\mathrm{Ct}$ method $\left(2^{-\Delta \Delta \mathrm{Ct}}\right)$ of relative quantification using $\beta$-actin as the control gene and the 0 -h endotoxin stimulation time point as the calibrator. 
Table 1. Gene targets and primer sequences for real-time PCR

\begin{tabular}{|c|c|c|c|}
\hline Target & Accession\# & & Sequence $\left(5^{\prime}\right.$ to $\left.3^{\prime}\right)$ \\
\hline \multirow[t]{3}{*}{ ICAM-1 } & \multirow[t]{3}{*}{ NM-174348 } & Forward & GCAGGTGGTCCACAAACAC \\
\hline & & Reverse & GCAATCCCGCTGGTCTAGTC \\
\hline & & Probe & ATGTCCTGTACGGCCCC \\
\hline \multirow[t]{3}{*}{ IL-1 $\beta$} & \multirow[t]{3}{*}{ NM-174093 } & Forward & GCTCTCCACCTCCTCTCACA \\
\hline & & Reverse & CTCTCCTTGCACAAAGCTCATG \\
\hline & & Probe & CAGAACACCACTTCTCG \\
\hline \multirow{3}{*}{ IL-8 } & \multirow{3}{*}{ NL-173925 } & Forward & GCTCTCTTGGCAGCTTTCCT \\
\hline & & Reverse & GGCATCGAAGTTCTGTACTCATTCT \\
\hline & & Probe & CAGAACTGCAGCTTCAC \\
\hline \multirow[t]{3}{*}{ TNF- $\alpha$} & \multirow[t]{3}{*}{ NM-173966 } & Forward & GCCCCCAGAGGGAAGAG \\
\hline & & Reverse & CCAGAGGGCTGTTGATGGA \\
\hline & & Probe & CCCCAGGTGGCCCC \\
\hline \multirow[t]{3}{*}{$\beta$-Actin } & \multirow[t]{3}{*}{ NM-173979 } & Forward & CCGCCCCGCTAGCA \\
\hline & & Reverse & AACTGGTTGCGGTGTCGA \\
\hline & & Probe & CCTTCGCCGCTCCGC \\
\hline
\end{tabular}

\section{Western Blot Analysis of ICAM1}

Whole cell lysates were harvested in M-Per reagent (Pierce, Rockford, IL) and centrifuged at $9,000 \times g$ for $10 \mathrm{~min}$ at $4^{\circ} \mathrm{C}$ to remove membrane fractions. Equal amounts of protein $(20$ to $30 \mu \mathrm{g})$ were resolved on a 10 to $15 \%$ SDS-PAGE gel and transferred to a nitrocellulose membrane. The membrane was blocked in 5\% dry milk in Tris-buffered saline (TBS) with $0.01 \%$ Tween-20 at room temperature and incubated with anti-human ICAM1 (1:1,000 dilution) overnight in $5 \%$ bovine serum albumin in TBS with $0.01 \%$ Tween-20. The membrane was incubated with secondary antibody to mouse IgGhorseradish peroxidase (HRP; 1:5,000 dilution) for 1 $\mathrm{h}$ at room temperature, washed, and exposed to HRP substrate (Pierce) and visualized by chemiluminescence on autoradiography film. The membrane was stripped and reblotted under similar conditions with anti-human actin (Chemicon, 1:5,000) followed by antimouse IgG-HRP secondary antibody (1:5,000 dilution).

\section{Statistical Analysis}

Statistical evaluation of the fold induction of proinflammatory mediator expression at each time point following endotoxin stimulation was conducted as repeated measures using a mixed model procedure (procedure MIXED, SAS Inst. Inc., Cary, NC). Least square means were separated by the Tukey-Kramer option in SAS. The direct effects of PAF and PAF receptor antagonist on BMEC-derived cytokine and adhesion molecule expression were statistically evaluated using the Student's $t$-test. Results were considered as statistically significant at $P<0.05$.

\section{RESULTS AND DISCUSSION}

Efficient recruitment of neutrophils to the site of infection plays a pivotal role in the establishment of new intramammary coliform infections in dairy cattle (Hill et al., 1984). Several previous studies characterized changes in the innate immune response of mammary tissues following challenge with $E$. coli or endotoxin (Rainard and Riollet, 2006). There is very little information, however, concerning the specific mammary cell types responsible for eliciting the production of important proinflammatory mediators following exposure to bacterial endotoxin. Platelet activating factor is among the primary mediators released during gramnegative infection that can act synergistically with early proinflammatory cytokines to cause many of the detrimental effects associated with endotoxemia (Kingsnorth, 1996; Stafforini et al., 2003). Different cell types are capable of synthesizing PAF including platelets, leukocytes, macrophages, and endothelial cells in a variety of tissues. This study demonstrates for the first time that endotoxin can induce the biosynthesis of PAF in BMEC as well. Lyso-PAF-AcT is the ratelimiting enzyme needed for PAF biosynthesis in bovine endothelial cells (Cao et al., 2001). The present study showed that cultured BMEC had a significant increase in PAF biosynthesis as indicated by the enhanced LysoPAF-AcT activity within 30 min of endotoxin exposure (Figure 1). The activity of Lyso-PAF-AcT peaked at 1 $\mathrm{h}$ following endotoxin challenge, and then gradually declined to pre-challenge levels by $12 \mathrm{~h}$. These findings are consistent with previous studies that demonstrated an early role of PAF in endotoxin-induced neutrophil accumulation in the bovine teat cistern (Persson et al., 1993; Waller, 1997). Exposure of mammary tissues to endotoxin can initiate a complex cascade of proinflammatory events involving many mediators produced by a variety of cells including macrophages and epithelial cells (Rainard and Riollet, 2006). The rapid biosynthesis of vascular-derived PAF following endotoxin exposure reported in this study supports an important role 


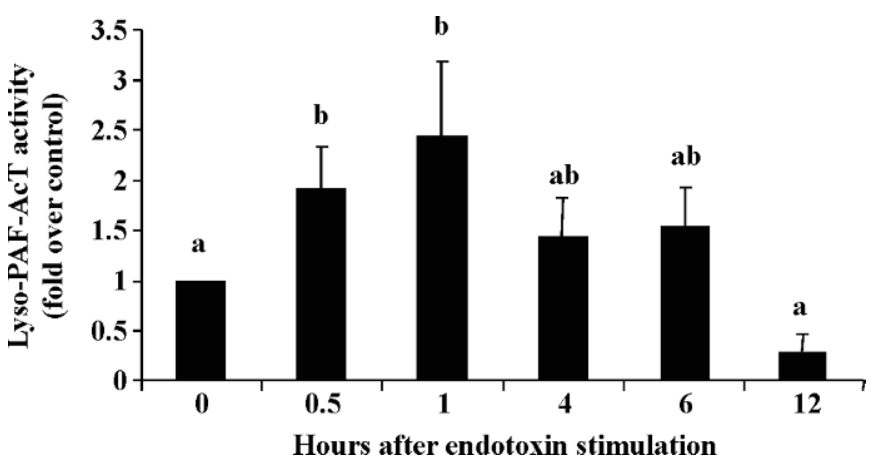

Figure 1. Changes in lyso-platelet activating factor (PAF) acetyl coenzyme A acetyltransferase (Lyso-PAF-AcT) activity in bovine mammary endothelial cells (BMEC) following endotoxin stimulation. Isolated BMEC were treated in culture with $100 \mathrm{ng} / \mathrm{mL}$ of endotoxin for 0.5 to $12 \mathrm{~h}$. The activity of Lyso-PAF-AcT was measured using thin layer chromatography and by detection of PAF biosynthesis utilizing $\left[1-{ }^{14} \mathrm{C}\right]$-acetyl coenzyme A. Data are expressed as fold over 0 -h control BMEC that were not treated with endotoxin and are expressed as means \pm SEM for 4 separate experiments. ${ }^{\mathrm{a}, \mathrm{b}}$ Means without a common letter differ significantly $(P<0.05)$

for BMEC in contributing to the early inflammatory response during coliform mastitis as well.

Platelet activating factor is derived from the phospholipids of cell membranes and is synthesized via 2 independent enzymatic pathways: the de novo pathway and the remodeling pathway. Endogenous PAF required for physiological functions in resting cells is formed by the de novo pathway, but the remodeling pathway is responsible for the biosynthesis of PAF in response to cellular stimulation by agonists, including endotoxin. In the remodeling pathway, phospholipase $\mathrm{A}_{2}$ catalyzes the structural modification of a membrane lipid (1-alkyl-2-acyl-sn-glycerol-3-phosphocholine) to produce lyso-PAF. The enzyme Lyso-PAF-AcT then introduces an acetyl residue from acetyl-coenzyme $\mathrm{A}$ at the $s n-2$ position of the glycerol backbone, yielding the vasoactive PAF. The insertion of the acetate at the $s n-2$ position is necessary for PAF bioactivity. Conversely, $\mathrm{PAF}-\mathrm{AH}$ can cleave the acetyl chain at the $s n-2$ position and play a major role in inhibiting PAF activity. Hence, it is possible that PAF-mediated inflammatory conditions could be regulated by both anabolic and catabolic enzymes of the remodeling pathway. The activity of the PAF catabolic enzyme, PAF-AH, did not change in BMEC following endotoxin challenge (Figure 2). These findings are consistent with our earlier studies that showed $\mathrm{TNF} \alpha$-induced vascular PAF biosynthesis resulted from an increase in anabolic enzyme activity without affecting the degradation of newly formed PAF by PAF-AH (Cao et al., 2001). Others also showed that PAF-AH mRNA expression did not change in tissues obtained from endotoxin-challenged mammary glands (Schmitz et al., 2004). The authors concluded that PAF

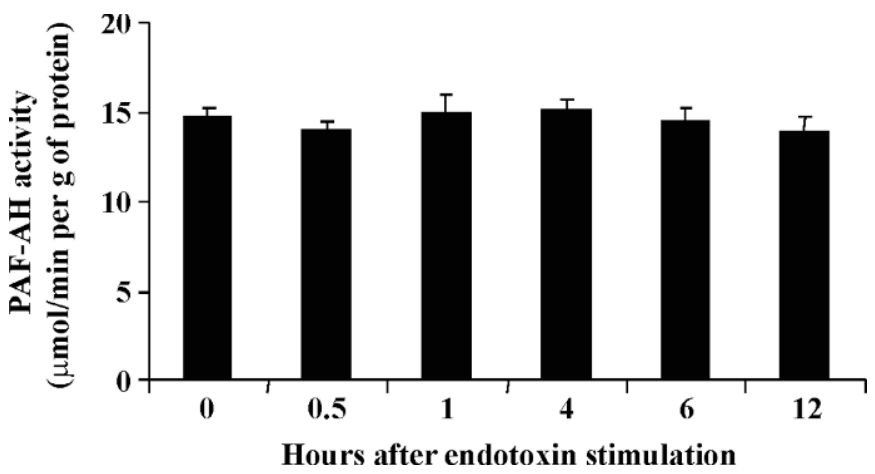

Figure 2. Changes in platelet activating factor acetylhydrolase (PAF-AH) activity in bovine mammary endothelial cells (BMEC) following endotoxin stimulation. Isolated BMEC were treated in culture with $100 \mathrm{ng} / \mathrm{mL}$ of endotoxin for 0.5 to $12 \mathrm{~h}$. The activity of PAF-AH was measured using the Cayman Chemical PAF-AH Activity Assay Kit. Data are expressed as means \pm SEM PAF-AH activity $(\mu \mathrm{mol} /$ $\mathrm{min} / \mathrm{g}$ of protein) for 3 separate experiments. The 0 -h time point represents control BMEC that were not treated with endotoxin.

was not likely involved in the short-term response of the mammary gland to endotoxin because expression of PAF-AH did not change as a function of treatment (Schmitz et al., 2004). The results from this study, however, dispute the conclusion that PAF does not have a role in early innate defense of the bovine mammary gland. As shown in this study and in our previous work (Cao et al., 2001; Corl et al., 2003), PAF biosynthesis is dependent on the relative expression of both anabolic and catabolic enzymes, and measures of only PAF-AH expression will not provide an accurate assessment of overall PAF biosynthesis. Moreover, the previous study by Schmitz et al. (2004) was conducted with whole mammary tissue samples and did not consider the contribution of individual cell populations, such as the vascular endothelium, to the relative pool of genes expressed during endotoxin challenge. The release of PAF is recognized as one of the earliest events in inflammation and vascular injury in a variety of tissues (Stafforini et al., 2003). The data presented here support the contention that PAF plays an early role in mammary vascular inflammatory responses as well.

Increased acute phase cytokine production is known to be an important component of bovine mammary gland innate immune responses to gram-negative infections. Studies dating back to almost 2 decades showed that $\mathrm{TNF} \alpha$, IL- $1 \beta$, and IL- 8 are expressed in the milk and sera of dairy cows during endotoxin or $E$. coli challenge (Sordillo and Peel, 1992; Shuster et al., 1993, 1996; Riollet et al., 2000). Several recent studies also confirmed the importance of these potent proinflammatory mediators when examined in mammary tissue samples, mammary leukocyte populations, and mammary epithelial cells following endotoxin exposure (Lee 
et al., 2006; Rainard and Riollet, 2006). We report for the first time, however, the expression of IL- $1 \beta$ and IL8 mRNA by BMEC in response to endotoxin challenge. This study focused on these vascular-derived proinflammatory cytokines because they are closely linked with leukocyte adhesion and activation during the early stages of inflammation. Incubation of BMEC with endotoxin resulted in a significant increase in both IL-1 $\beta$ and IL-8 mRNA expression beginning as soon as $1 \mathrm{~h}$ following challenge (Figures $3 \mathrm{~A}$ and $3 \mathrm{~B}$ ). The expression of IL-8 mRNA reached peak levels first at $1 \mathrm{~h}$ following challenge and remained relatively constant at this peak level through the 12-h sampling period (Figure 3B). The peak IL-1 $\beta$ response occurred later than IL-8 with maximal mRNA expression occurring from 4 to $12 \mathrm{~h}$ in culture. Especially noteworthy, however, is the magnitude of IL- $1 \beta$ mRNA change with over a 500-fold increase at $4 \mathrm{~h}$ and a 4,000-fold increase at $12 \mathrm{~h}$ when compared with the prechallenge control (Figure 3A). Increased expression of cytokine transcripts, however, does not always result in a corresponding increase in biologically active protein. For example, IL- $1 \beta$ is first synthesized as a larger precursor molecule that lacks a signal sequence needed for transport out of the cell. This larger pro-IL-1 $\beta$ remains in the cytosol unless cleaved by caspase- 1 into the mature form of IL$1 \beta$ that is released by the cell. It is the mature form of IL-1 $\beta$ that possesses optimal biological activity (Dinarello, 1998). Therefore, the 4,000-fold increase in IL-1 $\beta$ transcript expression may not necessarily correlate to biologically active protein. A similar trend in cytokine kinetics was observed, however, when IL-1 $\beta$ and IL-8 protein were measured in the milk and afferent lymph of the supramammary lymph nodes after intramammary infusion of endotoxin (Persson Waller et al., 2003). These earlier studies reported an early increase of IL8 in the afferent lymph and milk as soon as $2 \mathrm{~h}$, whereas IL-1 $\beta$ was not detected in milk until $4 \mathrm{~h}$ following endotoxin challenge (Persson Waller et al., 2003). The results from the present study would suggest that at least some of the IL- 8 observed in the afferent lymph could be vascular derived and not only from epithelial or leukocyte sources in the mammary tissue. Acute phase cytokines, including IL-1 $\beta$ and IL-8, are expressed transiently and often act locally in the tissue microenvironment. These proinflammatory cytokines function not only as potent chemoattractants, but can also enhance the functional activity of neutrophils as they migrate toward the infected mammary tissues (Rainard and Riollet, 2006). The dramatic and sustained increase in IL-1 $\beta$ and IL-8 mRNA from endotoxin-challenged BMEC suggests that these vascular-derived proinflammatory cytokines may play a significant role in
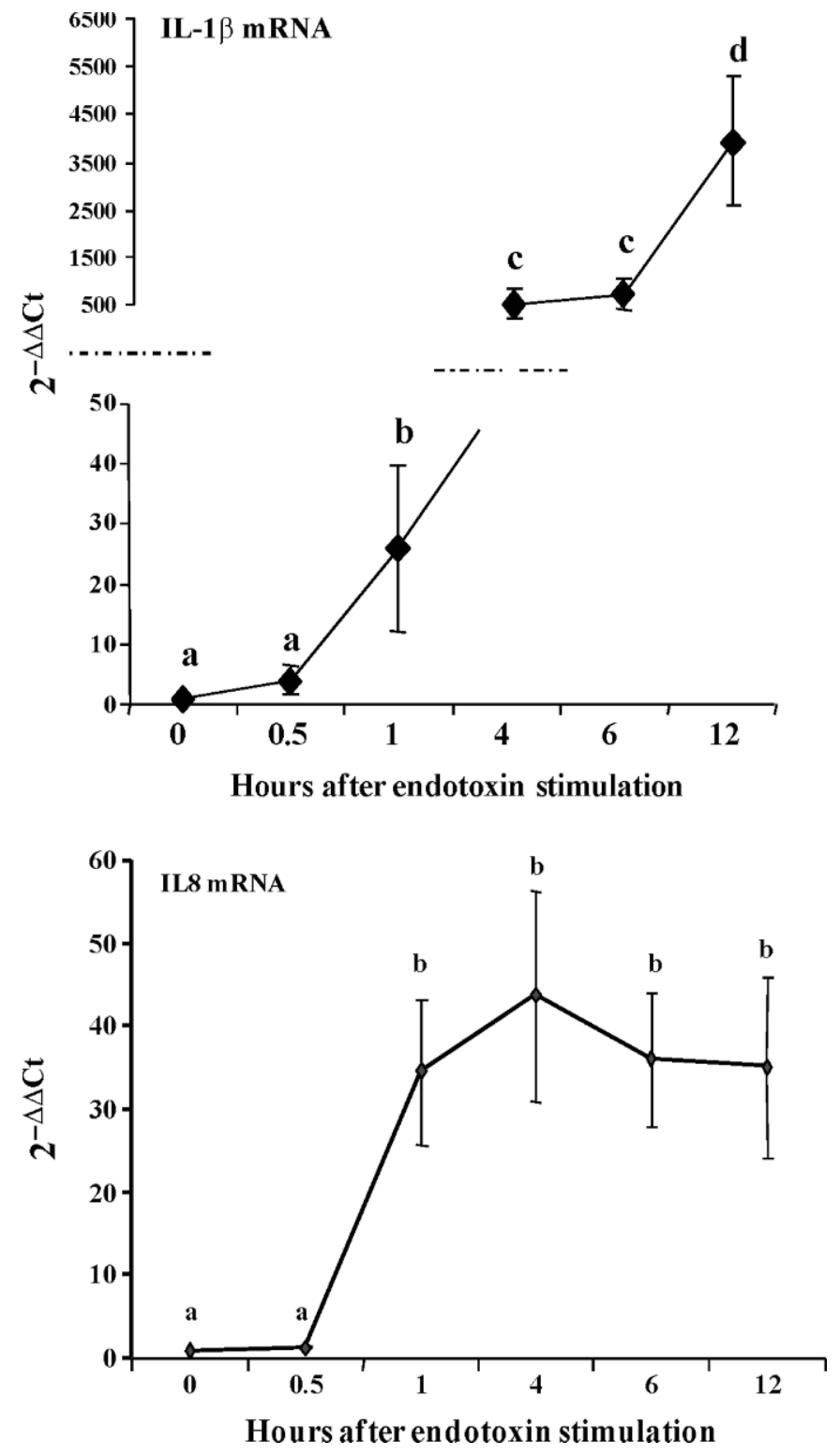

Figure 3. Changes in proinflammatory gene expression in bovine mammary endothelial cells (BMEC) following endotoxin stimulation. Isolated BMEC were treated in culture with $100 \mathrm{ng} / \mathrm{mL}$ of endotoxin for 0.5 to $12 \mathrm{~h}$. The RNA was isolated at each time point, and detection of IL-1 $\beta$ (A) and IL-8 (B) mRNA was evaluated by real-time PCR. Data represent the $2^{-\Delta \Delta \mathrm{Ct}}$ value using the 0 -h control BMEC that were not treated with endotoxin as the calibrator and are expressed as means \pm SEM for 3 separate experiments. ${ }^{a-d}$ Means without a common letter differ significantly $(P<0.05)$.

perpetuating the uncontrolled acute inflammatory response associated with clinical coliform mastitis.

The migration of leukocytes across endothelial cells and into underlying tissue is regulated, in part, through the expression of vascular adhesion molecules, including ICAM1. This important vascular adhesion molecule is constitutively expressed on endothelial cells, but can 

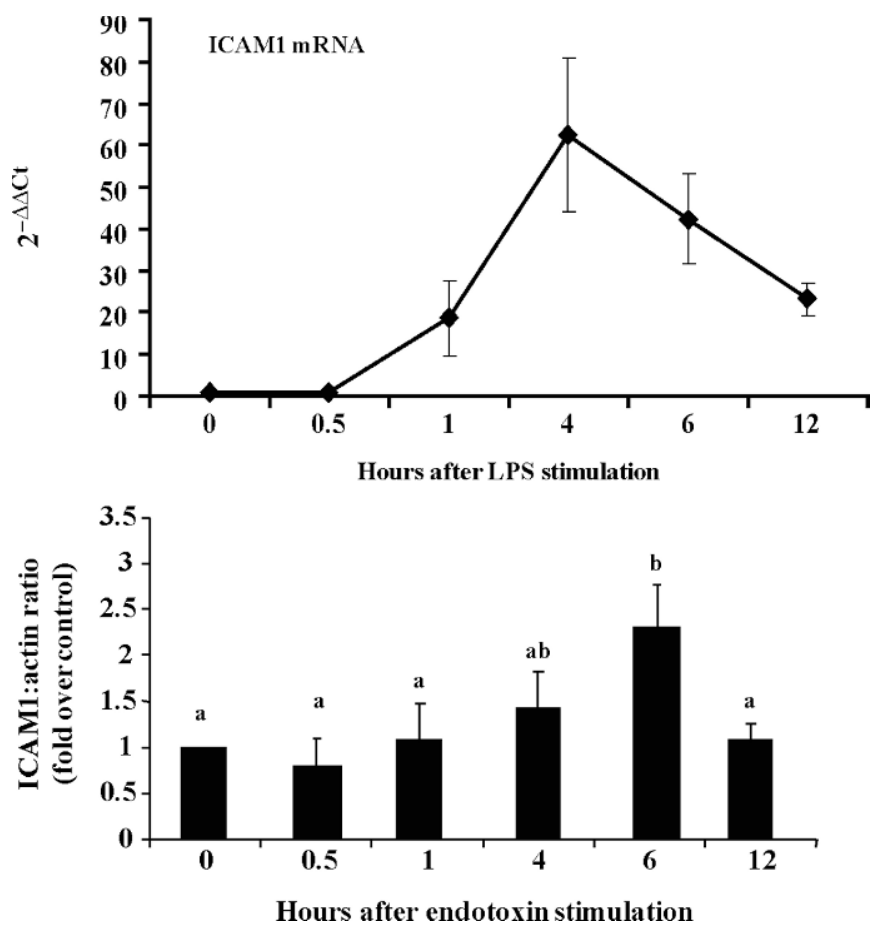

Figure 4. Changes in proinflammatory gene expression in bovine mammary endothelial cells (BMEC) following endotoxin stimulation. Isolated BMEC were treated in culture with $100 \mathrm{ng} / \mathrm{mL}$ of endotoxin for 0.5 to $12 \mathrm{~h}$. (A) RNA was isolated at each time point and detection of ICAM1 mRNA was evaluated by real-time PCR. Data represent the $2^{-\Delta \Delta \mathrm{Ct}}$ values using the 0 -h control BMEC that were not treated with endotoxin as the calibrator and are expressed as means \pm SEM for 3 separate experiments. (B) Whole-cell lysates were harvested, equal amounts of protein were resolved by $12 \%$ SDS-PAGE, and a Western blot was performed using bovine cross-reactive antibodies to ICAM1. Results are expressed as fold increase of ICAM1 protein/ actin ratio over the 0 -h control protein/actin ratio of BMEC that were not treated with endotoxin. ${ }^{\mathrm{a}, \mathrm{b}}$ Means $(\mathrm{n}=3)$ without a common letter differ significantly $(P<0.05)$.

be upregulated on activated endothelium in response to cytokines or endotoxin and plays a significant role in mediating early inflammatory events (Cines et al., 1998; Maddox et al., 1999). Considerable evidence also suggests that enhanced expression of ICAM1 can lead to vascular dysfunction and contribute to the development of several inflammatory-based diseases including atherosclerosis (Reiss and Glass, 2006). The potential role of altered ICAM1 expression during bovine mastitis, however, is not known. This study describes for the first time how the expression kinetics of ICAM1 change in BMEC following endotoxin challenge. A significant increase in ICAM1 mRNA expression was observed as early as $1 \mathrm{~h}$, but reached peak expression at $4 \mathrm{~h}$ following endotoxin stimulation (Figure 4A). Although not as sensitive as the real-time PCR data, Western blot analyses confirm a significant increase in ICAM1 protein expression in BMEC at $6 \mathrm{~h}$ following endotoxin stimulation (Figure 4B). These findings are consistent with our earlier studies that described a rapid increase in both ICAM1 mRNA expression and neutrophil adherence to BMEC within 3 to $6 \mathrm{~h}$ following IL- $\beta$ or TNF $\alpha$ stimulation (Maddox et al., 1999). An interesting finding with this study is that the expression of ICAM1 mRNA in endotoxin-stimulated BMEC began to gradually decrease after $4 \mathrm{~h}$ of stimulation with endotoxin and continuing through to the 12 -h time point. Whereas the expression of ICAM1 mRNA was still significantly higher at the 12-h period when compared with prechallenged controls, it appears that endotoxin stimulation did not sustain adhesion molecule expression to the same extent as the acute phase cytokines (Figures 3A and 3B). The gradual decline in ICAM1 mRNA expression at $6 \mathrm{~h}$, however, did follow the gradual decline in Lyso-PAF-AcT activity beginning at $4 \mathrm{~h}$ (Figure 1). Moreover, the significant increase of endotoxin-induced PAF biosynthesis at 30 min following challenge appears to precede the enhanced expression of IL-1 $\beta$, IL-8, and ICAM1 mRNA. Based on these descriptive changes in proinflammatory molecule expression, it was conjectured that the immediate PAF biosynthesis following endotoxin challenge may play a role in the regulation of subsequent vascular-derived cytokine and adhesion molecule expression. These findings are consistent with previous reports that suggest $\mathrm{PAF}$ can prime tissues for enhanced cytokine production (Braquet et al., 1989a,b; Snyder, 1995).

The potential effects of PAF biosynthesis on endotoxin-induced proinflammatory responses in BMEC was investigated using a selective $\mathrm{PAF}$ receptor antagonist (CV3988). The in vitro dose of CV3988 (10 $\mu M)$ used in this study was based on previously published reports on human endothelial cells (Mayer et al., 2002) and preliminary dose titrations conducted in our laboratory that showed 5 to $10 \mu M$ CV3988 added to BMEC culture could effectively reduce endotoxin-induced proinflammatory gene expression without altering cell viability (data not shown). Additional preliminary studies also showed that $10 \mu M$ CV3988 alone did not affect cytokine or adhesion molecule mRNA expression when expressed as fold change over untreated BMEC (IL-1 $\beta$, $0.88 \pm 0.32$; IL-8, $2.1 \pm 0.53$; ICAM1, $1.06 \pm 0.04)$. This study did find that treatment of BMEC with CV3988 significantly reduced vascular-derived IL- $1 \beta$, IL-8, and ICAM1 mRNA expression following $1 \mathrm{~h}$ stimulation with endotoxin (Figure 5). These data suggest that at least some of the proinflammatory gene responses in BMEC following endotoxin involve PAF receptor-mediated events. The involvement of the PAF receptor also suggests the possibility that endogenous PAF biosynthesis following endotoxin challenge may have a direct or indirect role in the expression of other important 


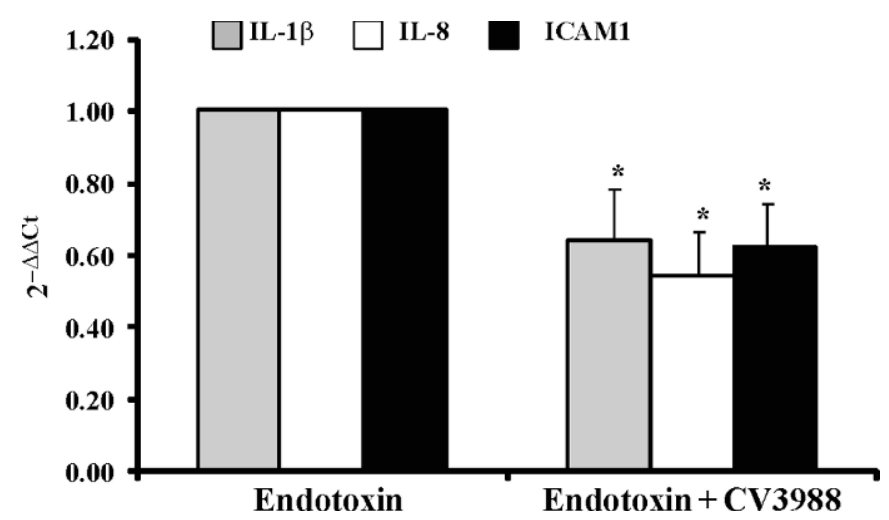

Figure 5. Effect of endogenous platelet activating factor (PAF) on proinflammatory gene expression in bovine mammary endothelial cells (BMEC) following endotoxin stimulation. Endotoxin-stimulated $(100 \mathrm{ng} / \mathrm{mL})$ BMEC were untreated or treated with $10 \mu M$ of a PAF receptor antagonist (CV3988). All treatments were carried out for 1 $\mathrm{h}$ before isolation of RNA for real-time PCR analyses of interleukin$1 \beta$ (IL-1 $\beta$ ), interleukin-8 (IL-8), and intercellular adhesion molecule 1 (ICAM1) mRNA expression. Data represent the $2^{-\Delta \Delta \mathrm{Ct}}$ values using the untreated control cultures as the calibrator and are expressed as means \pm SEM for 3 separate experiments. *Indicates a significant difference $(P<0.05)$ between the untreated and CV3988 groups for each mediator.

proinflammatory molecules in mammary endothelial cells. Therefore, the direct effects of PAF stimulation on proinflammatory gene expression also were examined to complement the CV3988 experiments. Treatment of BMEC with exogenous PAF for up to $4 \mathrm{~h}$ significantly increased IL- $1 \beta$ and IL-8 mRNA expression (sure 6). Although the exogenous PAF treatment did significantly increase cytokine mRNA expression in BMEC, it is worthy to note that the magnitude of the increase was not as great as that induced by 4-h endotoxin challenge (Figures $3 \mathrm{~A}$ and $3 \mathrm{~B}$ ). In contrast, exogenous PAF did not affect any changes in ICAM1 mRNA expression (Figure 6). Earlier studies also found that exogenous PAF alone was not able to increase ICAM1 expression, but instead required synergistic interactions with TNF- $\alpha$ to increase the adhesive properties of human umbilical vein endothelial cells (Sterner-Kock et al., 1996). They also showed that the synergistic increase in ICAM1 expression could be abolished when the endothelial cells were preincubated with a PAF receptor antagonist, confirming that ICAM1 expression was partially a PAF receptor-mediated event as shown in the present study. Collectively, results from this study do support a role for PAF and its receptor in the expression of IL-1 $\beta$, IL-8, and ICAM1 mRNA expression in BMEC. The influence of PAF alone on the expression of these important proinflammatory molecules, however, is not as pronounced when compared with changes in expression induced by endotoxin challenge.

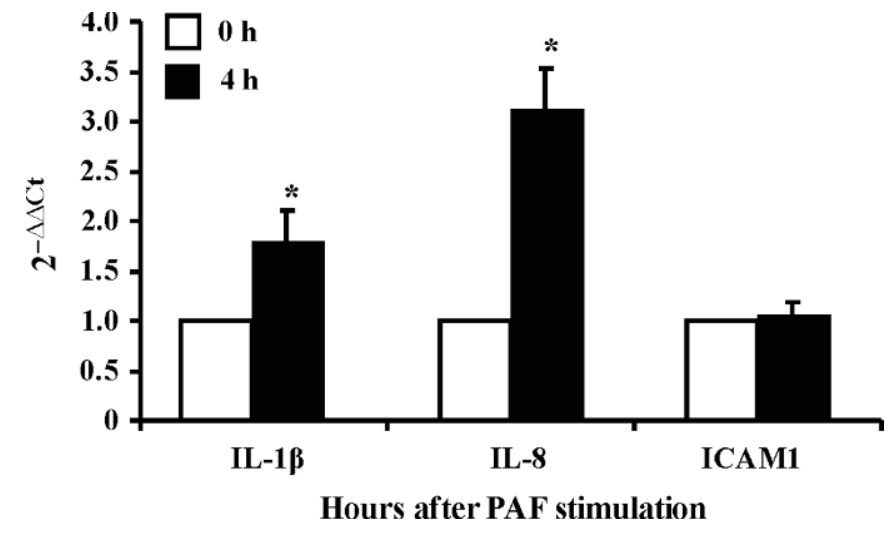

Figure 6. Effect of exogenous platelet activating factor (PAF) stimulation on proinflammatory gene expression in bovine mammary endothelial cells (BMEC). Isolated BMEC were either untreated or treated with $1 \mathrm{n} M$ PAF for $4 \mathrm{~h}$. Total RNA was isolated and interleukin-1 $\beta$ (IL-1 $\beta$ ), interleukin-8 (IL-8), and intercellular adhesion molecule 1 (ICAM1) mRNA were measured by real-time PCR. Data represent the $2^{-\Delta \Delta \mathrm{Ct}}$ values using the 0 -h control BMEC that were not treated with PAF as the calibrator and are expressed as means \pm SEM for 3 separate experiments. *Indicates a significant difference $(P<0.05)$ between the untreated and PAF-treated groups for each mediator.

The PAF receptor antagonist did have a greater impact on the suppression of endotoxin-induced gene regulation than the stimulation of BMEC with exogenous PAF. One possible explanation for these findings is that the PAF receptor may play a greater role in regulating endotoxin-induced BMEC proinflammatory gene responses other than through its interaction with PAF. For example, previous studies found that endotoxin was able to induce responses in Chinese hamster ovary cells only when the PAF receptor was expressed, and specific PAF binding could successfully displace and reversibly dissociate endotoxin binding (Nakamura et al., 1992). They also found that endotoxin-induced $\mathrm{Ca}^{2+}$ mobilization in platelets was effectively blocked by a selective PAF receptor antagonist and concluded that there may exist some cross-talk between endotoxin and the PAF receptor (Nakamura et al., 1992). Results from this study where the CV3988 had a more pronounced effect on silencing BMEC proinflammatory gene expression when compared with the stimulatory effects of the PAF add-back experiments would support the hypothesis of a direct relationship between endotoxin-induced gene regulation and the PAF receptor. The potential interaction of endotoxin and the PAF receptor in BMEC would be an interesting pathway to investigate in relationship to the pathogenesis of coliform mastitis in future studies.

Because vascular-derived PAF can at least partially influence proinflammatory gene responses of BMEC, additional experiments were conducted to elucidate 


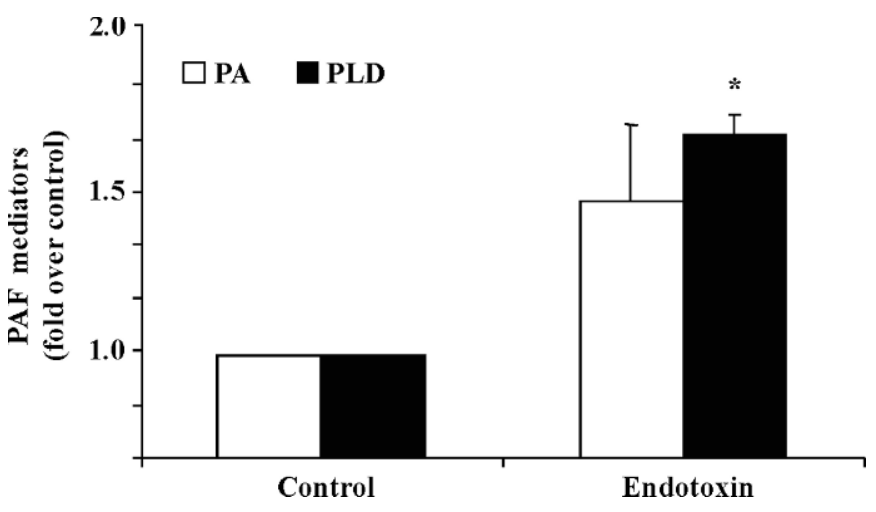

Figure 7. Changes in phosphatidic acid (PA) production and phospholipase D (PLD) activity in bovine mammary endothelial cells (BMEC) following endotoxin stimulation. Isolated BMEC were labeled with $\left[1_{-14} \mathrm{C}\right]$ arachidonic acid before stimulation with $100 \mathrm{ng} /$ $\mathrm{mL}$ of endotoxin for $30 \mathrm{~min}$. The formation of PA examined in 5 separate experiments and PLD activity determined in 3 separate experiments was measured using thin-layer chromatography. Data are expressed as fold over 0-h control BMEC that were not treated with endotoxin. *Indicates a significant difference $(P<0.05)$ between the untreated and endotoxin-treated groups for each mediator.

some factors that could be responsible for early PAF biosynthesis following endotoxin challenge. Phospholipase $\mathrm{D}$ is a ubiquitous enzyme located in plasma membranes that can catalyze the hydrolysis of the phosphodiester bond of glycerophospholipids to generate PA. In mammalian cells, PLD activity is tightly regulated and can play a significant role in cell signaling and membrane trafficking (Liscovitch et al., 2000). Phospholipase $\mathrm{D}$ also is associated with the development of several acute and chronic inflammatory disorders (Steed and Chow, 2001). The cellular activities associated with PLD are thought to be mediated by its direct downstream product, PA, which can act as an intracellular lipid messenger. Relative to this study, PA was reported to influence the activity of Lyso-PAF-AcT and PAF biosynthesis in certain cell populations including bovine endothelial cells (Garcia et al., 1993; Corl et al., 2003). To elucidate the potential mechanisms responsible for endotoxin-induced increases in Lyso-PAF-AcT activity in BMEC, changes in PLD activity and PA production were evaluated. This study showed for the first time a significant increase in PLD activity by endotoxinstimulated BMEC (Figure 7). An increase in PA production also was observed, but the increase was not statistically significant. Additional experiments using a selective PLD inhibitor or the addition of exogenous PA were conducted to determine if either of these lipid mediators was related directly to the PAF biosynthesis in endotoxin-challenged BMEC (Figure 8). Inhibition of PLD activity with calphostin $\mathrm{C}$ effectively blocked endotoxininduced Lyso-PAF-AcT activity in BMEC. The addition of exogenous PA to endotoxin-stimulated BMEC cul-

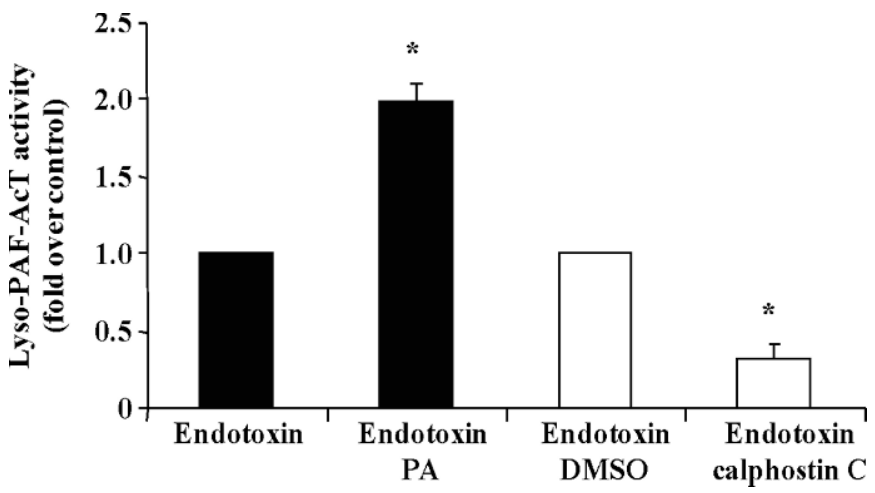

Figure 8. The effect of phosphatidic acid (PA) production and phospholipase D (PLD) activity on platelet activating factor (PAF) biosynthesis in bovine mammary endothelial cells (BMEC) following endotoxin stimulation. Isolated BMEC were pretreated with $60 \mu M$ PA for $2 \mathrm{~h}$ before a 1 -h stimulation with $100 \mathrm{ng} / \mathrm{mL}$ of endotoxin (black bars represent the mean for 3 separate experiments). Additional experiments were conducted where isolated BMEC were pretreated with a selective PLD inhibitor, calphostin C (150 nM), or vehicle control (DMSO) for $1 \mathrm{~h}$ before stimulation with $100 \mathrm{ng} / \mathrm{mL}$ of LPS for $1 \mathrm{~h}$ (white bars represent the mean for 3 separate experiments). Following stimulation, Lyso-PAF-AcT activity was measured by thinlayer chromatography. Data are expressed as fold over endotoxinstimulated BMEC that did not receive any pretreatments with PA or calphostin C. *Indicates a significant difference $(P<0.05)$ between the untreated and endotoxin-treated groups for each mediator.

tures, however, was able to significantly increase LysoPAF-Act activity over those cells stimulated with endotoxin alone (Figure 8). The findings from this study support the concept that increased PAF biosynthesis in endotoxin-stimulated BMEC is regulated, in part, by elevated PLD activity and PA production. These data are consistent with our earlier work that demonstrated a link between PLD, PA, and PAF biosynthesis in bovine aortic endothelial cells during oxidative stress (Corl et al., 2003).

\section{CONCLUSIONS}

The vascular endothelium is both a target for and cellular source of potent proinflammatory mediators such as PAF, IL-1 $\beta$, and IL-8. The production of these proinflammatory mediators and the expression of ICAM1 on endothelial cells are important innate defense mechanisms. The unregulated expression of proinflammatory factors, however, has been implicated in vascular dysfunction associated with gram-negative infections. This study described for the first time how $\mathrm{BMEC}$ respond to endotoxin challenge with respect to the kinetics of PAF, cytokine, and adhesion molecule expression. Vascular-derived PAF and its receptor is an early proinflammatory mediator that plays at least a partial role in the subsequent expression of IL- $1 \beta$, IL8 , and ICAM1 during endotoxin challenge. Further- 
more, endotoxin-induced PAF biosynthesis by BMEC is regulated to some extent by PLD activity and PA production. The mammary gland vasculature can contribute to the production of proinflammatory mediators that are typically associated with coliform mastitis. A better understanding of how vascular-derived PAF biosynthesis can impact the proinflammatory responses of BMEC to endotoxin may lead to effective strategies to disrupt excessive inflammatory responses during acute coliform mastitis.

\section{ACKNOWLEDGMENTS}

This work was supported in part by a grant from the National Research Initiative of the USDA Cooperative State Research, Education and Extension Service, grant number 2005-01681 and by an endowment from the Matilda R. Wilson Fund (Detroit, MI).

\section{REFERENCES}

Aherne, K. M., M. R. Davis, and L. M. Sordillo. 1995. Isolation and characterization of bovine mammary endothelial cells. Methods Cell Sci. 17:41-46.

Braquet, P., D. Hosford, M. Braquet, R. Bourgain, and F. Bussolino. 1989a. Role of cytokines and platelet-activating factor in microvascular immune injury. Int. Arch. Allergy Appl. Immunol. 88:88-100.

Braquet, P., M. Paubert-Braquet, R. H. Bourgain, F. Bussolino, and D. Hosford. 1989b. PAF/cytokine auto-generated feedback networks in microvascular immune injury: Consequences in shock, ischemia and graft rejection. J. Lipid Mediat. 1:75-112.

Bussolino, F., G. Camussi, and C. Baglioni. 1988. Synthesis and release of platelet-activating factor by human vascular endothelial cells treated with tumor necrosis factor or interleukin 1 alpha. J. Biol. Chem. 263:11856-11861.

Cao, Y. Z., Z. S. Cohen, J. A. Weaver, and L. M. Sordillo. 2001. Selenium modulates 1-O-alkyl-2-acetyl-sn-glycero-3-phosphocholine (PAF) biosynthesis in bovine aortic endothelial cells. Antioxid. Redox Signal. 3:1147-1152.

Caswell, J. L., D. M. Middleton, and J. R. Gordon. 1999. Production and functional characterization of recombinant bovine interleukin-8 as a specific neutrophil activator and chemoattractant. Vet. Immunol. Immunopathol. 67:327-340.

Cines, D. B., E. S. Pollak, C. A. Buck, J. Loscalzo, G. A. Zimmerman, R. P. McEver, J. S. Pober, T. M. Wick, B. A. Konkle, B. S. Schwartz, E. S. Barnathan, K. R. McCrae, B. A. Hug, A. M. Schmidt, and D. M. Stern. 1998. Endothelial cells in physiology and in the pathophysiology of vascular disorders. Blood 91:3527-3561.

Corl, C. M., Y. Z. Cao, Z. S. Cohen, and L. M. Sordillo. 2003. Oxidant stress enhances Lyso-PAF-AcT activity by modifying phospholipase $\mathrm{D}$ and phosphatidic acid in aortic endothelial cells. Biochem. Biophys. Res. Commun. 302:610-614.

Dinarello, C. A. 1998. Interleukin-1 beta, interleukin-18, and the interleukin-1 beta converting enzyme. Ann. N. Y. Acad. Sci. 856:1-11.

Garcia, C., M. Montero, J. Alvarez, and M. Sanchez Crespo. 1993. Biosynthesis of platelet-activating factor (PAF) induced by chemotactic peptide is modulated at the lyso-PAF:acetyl-CoA acetyltransferase level by calcium transient and phosphatidic acid. J. Biol. Chem. 268:4001-4008.

Grandel, U., and F. Grimminger. 2003. Endothelial responses to bacterial toxins in sepsis. Crit. Rev. Immunol. 23:267-299.

Hill, A. W., A. J. Frost, and B. E. Brooker. 1984. Progressive pathology of severe Escherichia coli mastitis in dairy cows. Res. Vet. Sci. 37:179-187.
Hogan, J., and K. Larry Smith. 2003. Coliform mastitis. Vet. Res. $34: 507-519$

Kingsnorth, A. N. 1996. Platelet-activating factor. Scand. J. Gastroenterol. Suppl. 219:28-31.

Kruse-Elliott, K. T., D. H. Albert, J. B. Summers, G. W. Carter, J. J. Zimmerman, and J. E. Grossman. 1996. Attenuation of endotoxininduced pathophysiology by a new potent PAF receptor antagonist. Shock 5:265-273.

Lee, J. W., D. D. Bannerman, M. J. Paape, M. K. Huang, and X. Zhao. 2006. Characterization of cytokine expression in milk somatic cells during intramammary infections with Escherichia coli or Staphylococcus aureus by real-time PCR. Vet. Res. 37:219-229.

Lee, S. J., K. Drabik, N. J. Van Wagoner, S. Lee, C. Choi, Y. Dong, and E. N. Benveniste. 2000. ICAM-1-induced expression of proinflammatory cytokines in astrocytes: Involvement of extracellular signal-regulated kinase and p38 mitogen-activated protein kinase pathways. J. Immunol. 165:4658-4666.

Liscovitch, M., M. Czarny, G. Fiucci, and X. Tang. 2000. Phospholipase D: Molecular and cell biology of a novel gene family. Biochem. J. 345:401-415.

Lohuis, J. A., Y. H. Schukken, J. H. Verheijden, A. Brand, and A. S. Van Miert. 1990. Effect of severity of systemic signs during the acute phase of experimentally induced Escherichia coli mastitis on milk production losses. J. Dairy Sci. 73:333-341.

Maddox, J. F., K. M. Aherne, C. C. Reddy, and L. M. Sordillo. 1999. Increased neutrophil adherence and adhesion molecule mRNA expression in endothelial cells during selenium deficiency. J. Leukoc. Biol. 65:658-664.

Mayer, K., M. Merfels, M. Muhly-Reinholz, S. Gokorsch, S. Rosseau, J. Lohmeyer, N. Schwarzer, M. Krull, N. Suttorp, F. Grimminger, and W. Seeger. 2002. Omega-3 fatty acids suppress monocyte adhesion to human endothelial cells: Role of endothelial PAF generation. Am. J. Physiol. Heart Circ. Physiol. 283:H811-H818.

Monfardini, E., M. J. Paape, Y. Wang, A. V. Capuco, M. Husheem, L. Wood, and C. Burvenich. 2002. Evaluation of L-selectin expression and assessment of protein tyrosine phosphorylation in bovine polymorphonuclear neutrophil leukocytes around parturition. Vet. Res. 33:271-281.

Nakamura, M., Z. Honda, I. Waga, T. Matsumoto, M. Noma, and T. Shimizu. 1992. Endotoxin transduces $\mathrm{Ca} 2+$ signaling via plateletactivating factor receptor. FEBS Lett. 314:125-129.

Persson, K., I. Larsson, and C. Hallen Sandgren. 1993. Effects of certain inflammatory mediators on bovine neutrophil migration in vivo and in vitro. Vet. Immunol. Immunopathol. 37:99-112.

Persson Waller, K., I. G. Colditz, S. Lun, and K. Ostensson. 2003. Cytokines in mammary lymph and milk during endotoxin-induced bovine mastitis. Res. Vet. Sci. 74:31-36.

Rainard, P., and C. Riollet. 2006. Innate immunity of the bovine mammary gland. Vet. Res. 37:369-400.

Reinhart, K., O. Bayer, F. Brunkhorst, and M. Meisner. 2002. Markers of endothelial damage in organ dysfunction and sepsis. Crit. Care Med. 30:S302-S312.

Reiss, A. B., and A. D. Glass. 2006. Atherosclerosis: Immune and inflammatory aspects. J. Investig. Med. 54:123-131.

Riollet, C., P. Rainard, and B. Poutrel. 2000. Differential induction of complement fragment $\mathrm{C} 5 \mathrm{a}$ and inflammatory cytokines during intramammary infections with Escherichia coli and Staphylococcus aureus. Clin. Diagn. Lab. Immunol. 7:161-167.

Schmitz, S., M. W. Pfaffl, H. H. Meyer, and R. M. Bruckmaier. 2004. Short-term changes of mRNA expression of various inflammatory factors and milk proteins in mammary tissue during LPS-induced mastitis. Domest. Anim. Endocrinol. 26:111-126.

Shuster, D. E., M. E. Kehrli, and M. G. Stevens. 1993. Cytokine production during endotoxin-induced mastitis in lactating dairy cows. Am. J. Vet. Res. 54:80-85.

Shuster, D. E., E. K. Lee, and M. E. Kehrli Jr. 1996. Bacterial growth, inflammatory cytokine production, and neutrophil recruitment during coliform mastitis in cows within ten days after calving, compared with cows at midlactation. Am. J. Vet. Res. 57:15691575.

Smith, K. L., J. H. Harrison, D. D. Hancock, D. A. Todhunter, and H. R. Conrad. 1984. Effect of vitamin E and selenium supplemen- 
tation on incidence of clinical mastitis and duration of clinical symptoms. J. Dairy Sci. 67:1293-1300.

Snapper, J. R., W. Lu, P. L. Lefferts, and J. S. Thabes. 1998. Effect of platelet-activating factor-receptor antagonism on endotoxininduced lung dysfunction in sheep. J. Appl. Physiol. 84:16101614.

Snyder, F. 1995. Platelet-activating factor and its analogs: Metabolic pathways and related intracellular processes. Biochim. Biophys. Acta 1254:231-249.

Sordillo, L. M., and J. E. Peel. 1992. Effect of interferon-gamma on the production of tumor necrosis factor during acute Escherichia coli mastitis. J. Dairy Sci. 75:2119-2125.

Stafforini, D. M., T. M. McIntyre, G. A. Zimmerman, and S. M. Prescott. 2003. Platelet-activating factor, a pleiotrophic mediator of physiological and pathological processes. Crit. Rev. Clin. Lab. Sci. 40:643-672.
Steed, P. M., and A. H. Chow. 2001. Intracellular signaling by phospholipase D as a therapeutic target. Curr. Pharm. Biotechnol. $2: 241-256$.

Sterner-Kock, A., R. K. Braun, M. D. Schrenzel, and D. M. Hyde. 1996. Recombinant tumour necrosis factor-alpha and plateletactivating factor synergistically increase intercellular adhesion molecule-1 and E-selectin-dependent neutrophil adherence to endothelium in vitro. Immunology 87:454-460.

von der Thusen, J. H., J. Kuiper, T. J. van Berkel, and E. A. Biessen. 2003. Interleukins in atherosclerosis: Molecular pathways and therapeutic potential. Pharmacol. Rev. 55:133-166.

Waller, K. P. 1997. Modulation of endotoxin-induced inflammation in the bovine teat using antagonists/inhibitors to leukotrienes, platelet activating factor and interleukin 1 beta. Vet. Immunol. Immunopathol. 57:239-251. 